PRODUCTION

ENGINEERING ARCHIVES
2014, Vol. 2, No. 1, pp 26 - 32

ISSN 2353-5156 (print version)

ISSN 2353-7779 (online version)

\title{
Effect of laser surface treatment on the quality of microstructure in recycled Al-Zn-Si cast alloy
}

\author{
Eva Tillová ${ }^{1}$, Emília Ďuriníková ${ }^{1}$, Mária Chalupová ${ }^{1}$, Norbert Radek ${ }^{2}$ \\ ${ }^{1}$ University of Žilina, Faculty of Mechanical Engineering, Department of Material Engineering, Univerzitná 8215/1, 010 26 Žilina, Slovakia \\ ${ }^{2}$ Technical University of Kielce, Chair of Terotechnology, The Centre for Laser Technologies of Metals, Al. 1000-lecia Państwa Polskiego \\ 7, 25-314 Kielce, Poland
}

\begin{abstract}
Recycled Al-Zn-Si casting alloys can often be used in new cast products for mechanical engineering, in hydraulic castings, textile machinery parts, cable car components or big parts without heat treatment. Improved mechanical properties and favourable of recycled microstructure of Al-alloys can often significantly increase the lifetime of casting and reduce costs for fuel and reduction of environmental loading. The paper is focused on using one of possible technologies that provide increased mechanical properties of recycled aluminium cast alloys for automotive industry, and that is laser surface hardening. For study was used recycled AlZn10Si8Mg cast alloy. The effect of laser beam Nd: YAG lasers BLS 720 was evaluated with the laser power $50 \mathrm{~W}$ and $80 \mathrm{~W}$ on the surface of samples. The final microstructure of aluminium alloys depend on the laser process parameters. The changes of microstructure as a grain refinement of the microstructure after laser surface hardening was observed by using classical techniques of etching and deep etching with concentrated $\mathrm{HCl}$. Microstructure was evaluated on an optical microscope Neophot 32 and SEM.
\end{abstract}

Key words: secondary cast alloy, laser surface treatment, microstructure

\section{Introduction}

The aluminium industry is committed to securing business success in automotive industry and continued growth towards a more sustainable economy of the future. It will achieve this by progressively improving its environmental, occupational health and safety (http://world-aluminium.org). The industry employs a lifecycle approach to address the challenges of climate change, focusing not only on the energy required to produce aluminium products but also on the energy savings to be made through their use and reuse (BORKOWSKI S., KNOP K. 2013).
Recycled Al-Zn-Si casting alloys can often be used in new cast products for mechanical engineering, in hydraulic castings, textile machinery parts, cable car components or big parts without heat treatment (www.sag.at). Improved mechanical properties and favourable of secondary structure of Al-alloys can often significantly increase the lifetime of casting and reduce costs for fuel and reduction of environmental loading. One way of increase the mechanical properties of castings is laser surface hardening of Al-cast alloys.

Laser irradiation is a well-established process technology for different industrial operations, such as metal cutting, drilling, welding and forming, but 
also widely applied for aluminium surface cleaning (WATKINS K. G. 2003), surface melting (WONG R. C. P. 1997; LI R. 1996) and surface alloying (WATKINS K. G. 1997; 1998). By the use of laser treatments for modifying surfaces to improve corrosion resistance and mechanical properties is the basic problem in surface heating substances laser radiation is well defined conditions of heating, which is necessary to specify the wavelength of radiation (laser type) to be used, but also the shape of the laser beam, for the interaction of laser radiation and matter, and we cannot forget the side effects that accompany a given technological operation. It is therefore necessary to define the basic physical processes in materials during heating laser beam generated.

In the operation of the laser beam for a time of the material leads to the conversion of absorbed optical energy to thermal energy, which heats a volume of material and depending on the temperature in that part of the volume phase transition occurs. It is therefore necessary to optimize the speed of energy input, power, duration of activity beam, material parameters etc. so that the process was effective and without adverse events (http://www.kme.elf.stuba.sk; http://www.woodlaserengraver.com/category/nd-yaglaser), those affecting the quality of the surface - the surface layer under the surface of in the material.

\section{Experimental procedure}

As an experimental material was used secondary (recycled) AlZn10Si8Mg cast alloy (UNIFONT ${ }^{\circledR}$ - 90) with very good casting properties, good wear resistance, low thermal expansion and very good machining (www.sag.at; www.alurheinfelden.com). Chemical composition of the alloy is given in the Table 1. Test bars (ø $20 \mathrm{~mm}$ with length $300 \mathrm{~mm}$ ) were produced by process sand casting in foundry UNEKO, s.r.o., Zátor, Ltd. Czech Republic. Sand casting is the simplest and most widely used casting method. The melt was not modified or grain refined.

Table 1.Chemical composition of secondary AlZn10Si8Mg cast alloy (wt. \%)

\begin{tabular}{|c|c|c|c|c|c|c|c|}
\hline Zn & Si & Cu & Fe & Mn & Mg & Ti & Al \\
\hline 9.6 & $\mathbf{8 . 6 4}$ & $\mathbf{0 . 0 0 5}$ & $\mathbf{0 . 1 1 4}$ & $\mathbf{0 . 1 8}$ & $\mathbf{0 . 4 5}$ & $\mathbf{0 . 0 6}$ & rest. \\
\hline
\end{tabular}

This alloy is made by recycling of scrap and separated waste (referred to as "secondary" alloys) and after sand casting have good mechanical properties tensile strength (220 - $250 \mathrm{MPa})$, offset $0.2 \%$ yield stress (190 - $230 \mathrm{MPa})$, however the low ductility limits $(1-2 \%)$, Brinell hardness HB $90-100$ (www.sag.at ; www.alurheinfelden.com, ĎURINÍKOVÁ, E. 2011). It is a self-hardening cast alloy and selfhardening starts when the castings are removed from the mould and the final mechanical properties are achieved after storage of approximately 7 to 10 days at room temperature. In the process of thin-walled castings self-hardening completed after 7 days and the thick-walled castings after 10 days.

Metallographic samples were prepared from selected specimens for bending impact toughness test (after testing) and the microstructures were examined by optical microscopy (Neophot 32) and scanning electron microscopy - SEM (VEGA LMU II). As-cast and laser treated specimens were sectioned and prepared by standards metallographic procedures (mounting in bakelite, wet ground, DP polished with diamond pastes, finally polished with commercial fine silica slurry (STRUERS OP-U) and etched by $10 \%$ H3PO4 during 10 minutes (to obtain black-white contrast) or by Weck-Al (to obtain colour contrast). Some samples were also deep-etched for $15 \mathrm{~s}$ in $\mathrm{HCl}$ solution in order to reveal the three-dimensional morphology of the eutectic silicon.

The specimen preparation procedure for deepetching consists of dissolving the aluminium matrix in a reagent that will not attack the eutectic components. The residuals of the etching products should be removed by intensive rinsing in alcohol. The preliminary preparation of the specimen is not necessary, but removing the superficial deformed or contaminated layer can shorten the process.

Experimental works (the laser surface treatment) were carried out in collaboration with Technical University of Kielce, The Centre for Laser Technologies of Metals, Poland.

The subsequent laser treatment (Fig. 1) was performed with the aid of a BLS 720 laser system employing the Nd: YAG type laser operating in the pulse mode, with a maximum average output of $150 \mathrm{~W}$. Laser hardening was carried out in an atmosphere of compressed air that was in the position of the laser 
blown. The laser beam has worked in the TEM00 mode. Nd: YAG (neodymium - doped yttrium aluminium garnet; $\mathrm{Nd}$ : Y3Al5O12) is a crystal that is used as a lasing medium for solid-state lasers.

The dopant, triply ionized neodymium, typically replaces yttrium in the crystal structure of the yttrium aluminium garnet (YAG), since they are of similar size. Generally the crystalline host is doped with around $1 \%$ neodymium by atomic percent. Neodymium ions in various types of ionic crystals, and also in glasses, act as a laser gain medium, typically emitting $1064 \mathrm{~nm}$ light from a particular atomic transition in the neodymium ion, after being ,pumped” into excitation from an external source (Fig. 2) (http://en.wikipedia.org/wiki/Nd:YAG_laser; http://www.woodlaserengraver.com/category/nd-yaglaser).

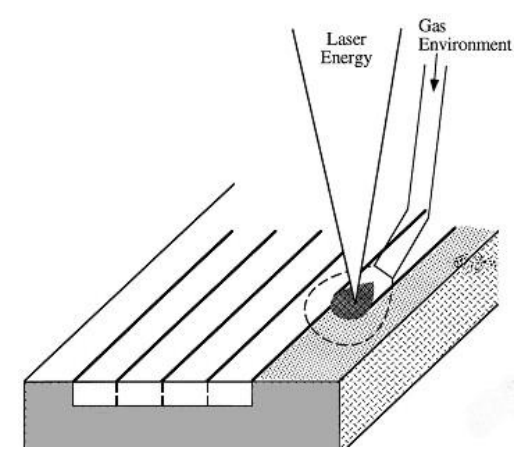

Fig. 1. Laser surface treatment

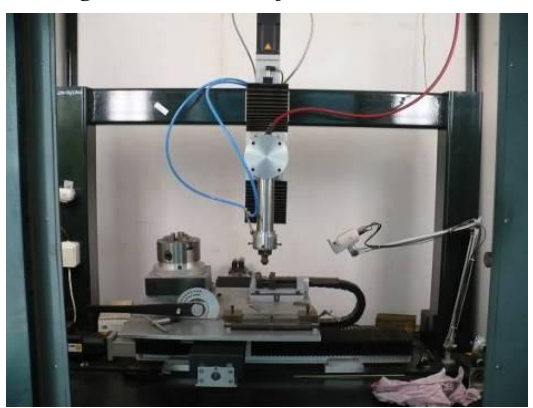

Fig. 2. Nd: YAG laser

The following parameters were assumed for the laser treatment:

- $\quad$ laser spot diameter $\mathrm{d}=0.7 \mathrm{~mm}$;

- beam shift rate $\mathrm{V}=250 \mathrm{~mm} / \mathrm{min}$;

- nozzle-sample distance $\mathrm{h}=6 \mathrm{~mm}$;

- pulse duration ti $=0.4 \mathrm{~ms}$;

- frequency $\mathrm{f}=50 \mathrm{~Hz}$;

- protective gas - nitrogen $\mathrm{Q}=25 \mathrm{l} / \mathrm{min}$;

- $\quad$ shift of beam $\mathrm{S}=0.4 \mathrm{~mm}$.

- laser pulse power $\mathrm{P}=50$ and $80 \mathrm{~W}$.
The quality of laser surface treatment of samples after laser action depends mainly on the form, length and average power or pulse power (GHENG $\mathrm{H}$. 2001).The presented experimental work was focused on the study of structural changes occurring in the material under the influence of different laser power $(\mathrm{P}=50$ and $80 \mathrm{~W})$. Test specimens in shape and size samples responded to bending impact test without notch $(10 \times 10 \times 55 \mathrm{~mm})$ and laser surface hardening was applied to one side of the sample (surface $10 \times 55$ $\mathrm{mm})$.

Microhardness measurement of samples surface affected by laser with different pulse power was performed by a Vickers hardness tester (Vickers Diamond Pyramid indenter is ground in the form of a squared pyramid with an angle of $136^{\circ}$ between faces) with load of $10 \mathrm{~g}$, and dwell time of $10 \mathrm{~s}$ (HV 0.01). The Vickers microhardness value at each state was obtained by an average of at least twenty measurements.

Quantitative metallography was carried out on an Image Analyzer NIS - Elements 3.0 to quantify incurred layer thickness by magnification $100 \mathrm{x}$.

\section{Results and discussion}

The microstructure of experimental material, scrap-based - recycled AlZn10Si8Mg cast alloy, consist of primary phase ( $\alpha$-solid solution), eutectic (mixture of $\alpha$-matrix and fine spherical Si-particles) and variously type's intermetallic phases (Chinese script, respectively skeleton-like phase $-\mathrm{Mg}_{2} \mathrm{Si}$, oval round like particles $\mathrm{Al}_{2} \mathrm{CuMg}$, long thin needles - Fe-rich phase - AlFeMnSi, sharp-edged or rounded particles $\mathrm{Al}(\mathrm{FeMn}) \mathrm{SiNi}$ and ternary eutectic $\left.\mathrm{Al}-\mathrm{MgZn}_{2}-\mathrm{Cu}\right)$. The typical dendritic microstructure of as-cast alloy with SDAS factor (secondary dendrite arm spacing) $64.65 \mu \mathrm{m}$ is present in Fig. 3 .

The $\alpha$-matrix precipitates from the liquid as the primary phase and is nominally comprised of $\mathrm{Al}$ and $\mathrm{Zn}$ (Fig. 3a). Eutectic is a dark brown crystals $\mathrm{Si}$ in $\alpha$ phase. Experimental material was not modified and so eutectic Si particles are like small grains of poorly rounded. Thickened grains were observed on the periphery of dendrites $\alpha$-phase (Fig. 3b). After deep etching (Fig. 3c, 3d) we can see that the silicon is crystallized in the form of bars, which grow clusters from a single nucleating site. 3-D form bars corresponds 
metallographic sections, i.e. bunchy in the middle of the arrangement prevailing fine round bars and outwards, we see increased incidence of so called plate type with typical hexagonal shape, characteristic for the non modified alloys.

a)

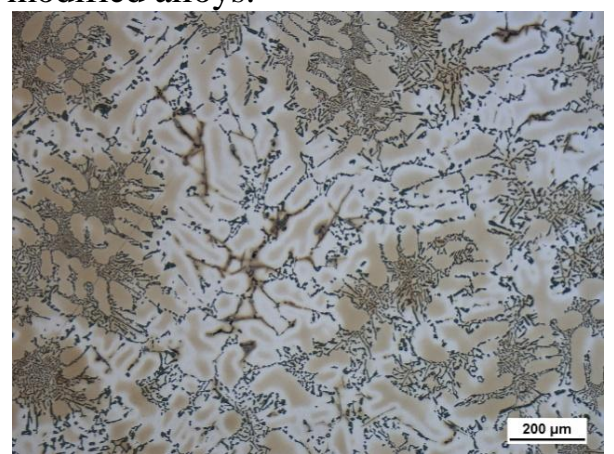

b)

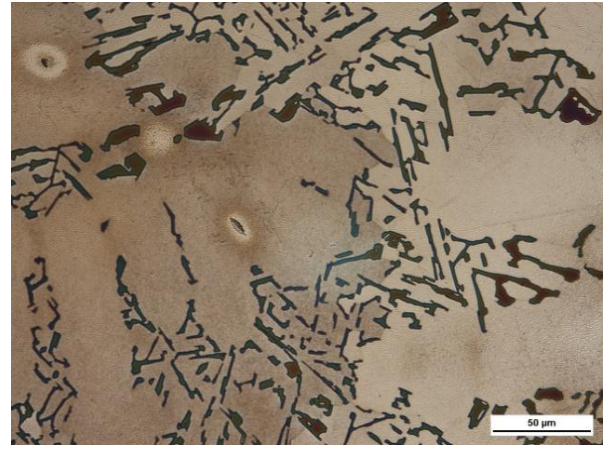

c)

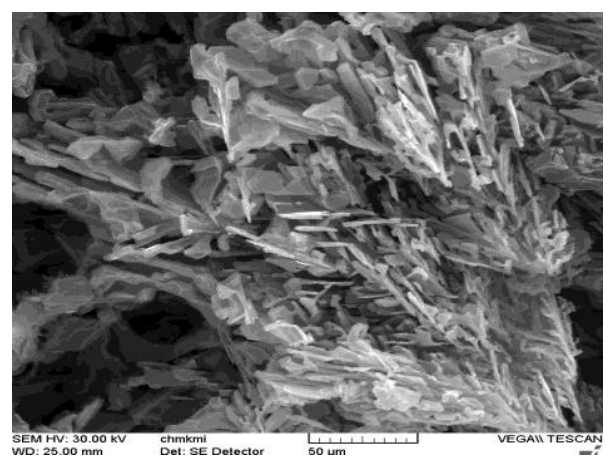

d)

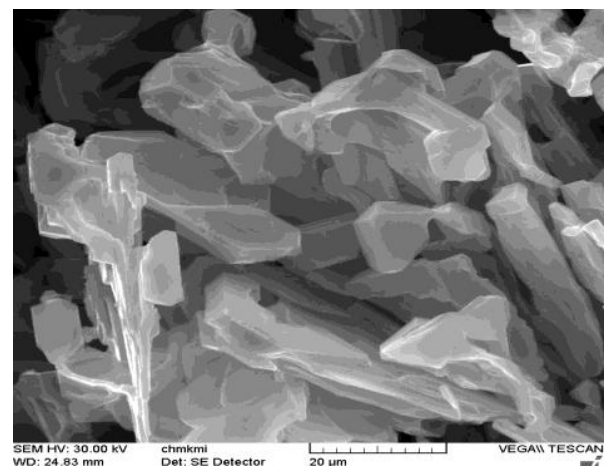

Fig. 3. Microstructure of AlZn10Si8Mg cast alloy: a) dendritic microstructure etch. Weck-Al, b) detail, etch. Weck-Al, c) morphology of Si particles, deep-etch. $\mathrm{HCl}$, SEM, d) detail of Si particles, deep-etch. $\mathrm{HCl}, \mathrm{SEM}$
As recycling of aluminium alloys becomes more common, sludge will be a problem of increasing importance due to the concentration of $\mathrm{Fe}, \mathrm{Mn}, \mathrm{Cr}$ and $\mathrm{Si}$ in the scrap cycle. During the industrial processing of the Al-Si alloys, these elements go into solid solution but they also form different intermetallic phases.

Intermetallic phases were observed with optical microscopy and SEM. These phases are on the basis of (Fig. 4) (D̃uRINÍKOVÁ E. 2010):

- Copper - phase Al2CuMg (Fig. 4 (1));

- Iron - phases AlFeMnSi (Fig. 4 (2)), AlFeMnMgSi or AlFeNi (Fig. 4 (3));

- Magnesium - Mg2Si (Fig. 4 (4));

- Zinc - MgZn2 (in ternary eutectic Al-MgZn2-Cu) (Fig. 4 (5)).

The cross-section of the microstructure of specimens after laser treatment is documented in Fig. 5. In crosssection are observed the remelting zone and the basic zone (Fig. 5a). The structural characteristic of the laser remelting zone are as follows. The structure of the laser treating alloy may be divided into four zones: I zone (the surface zone) is characterized by fine equiaxed grains with highly dispersed dendrites; II zone by larger equiaxed grains; III zone by column grains; IV zone by the dendrites that have the same orientation as the heat flowing, and is the transition zone between the columnar zone and the base alloy (Figures 5b, 5c).

The dendrites had a certain orientation. The growth direction of the dendrites in the melt pool bottom was perpendicular to the surface. Away from the bottom, the direction changed gradually into the parallel orientation to the surface, the growth direction of the dendrites in the melt pool related to the direction of heat transition.

Always is not possible to observe the separately zone, because the action of the laser beam on the sample surface is rapid heated to the melting point alloy. After removing the bond beam exposure surface of the sample is cooled at high speed, which greatly increases the nucleation rate. In addition to the centre of material is not enough time to grow dendrites $\alpha$-phase in all directions. 
a)

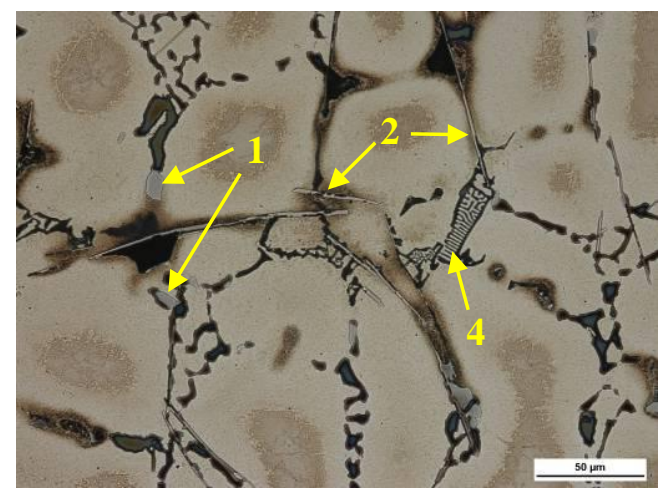

b)

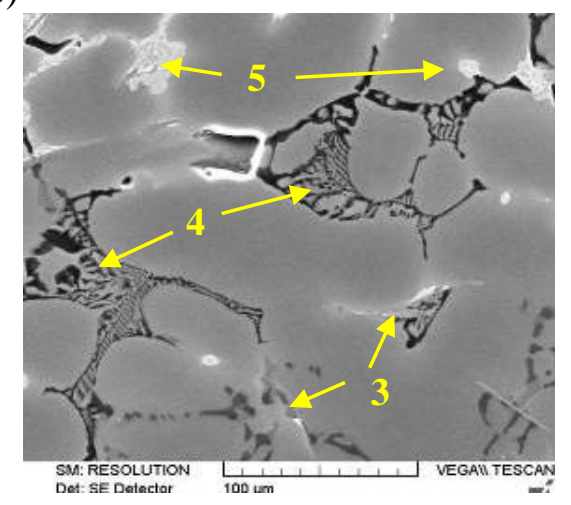

Fig. 4. Intermetallic phases: a) etch. Weck-Al, b) etch. $0.5 \% \mathrm{HF}$, SEM

a)

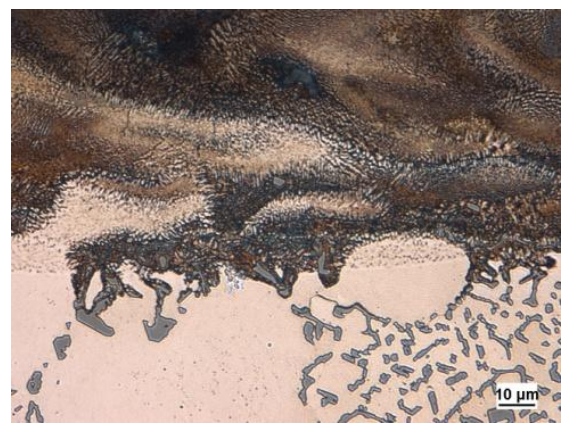

c)

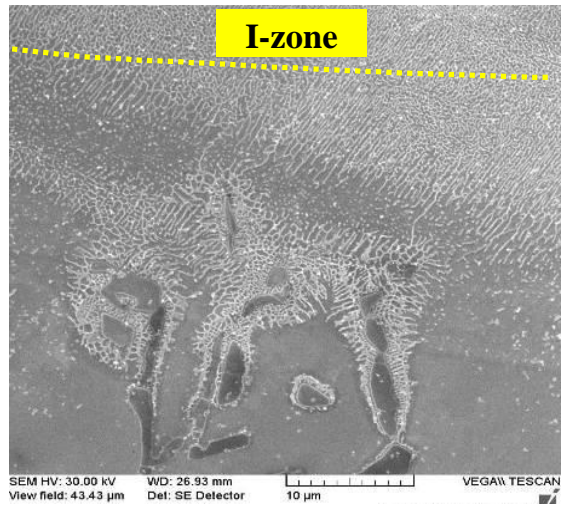

b)

d)
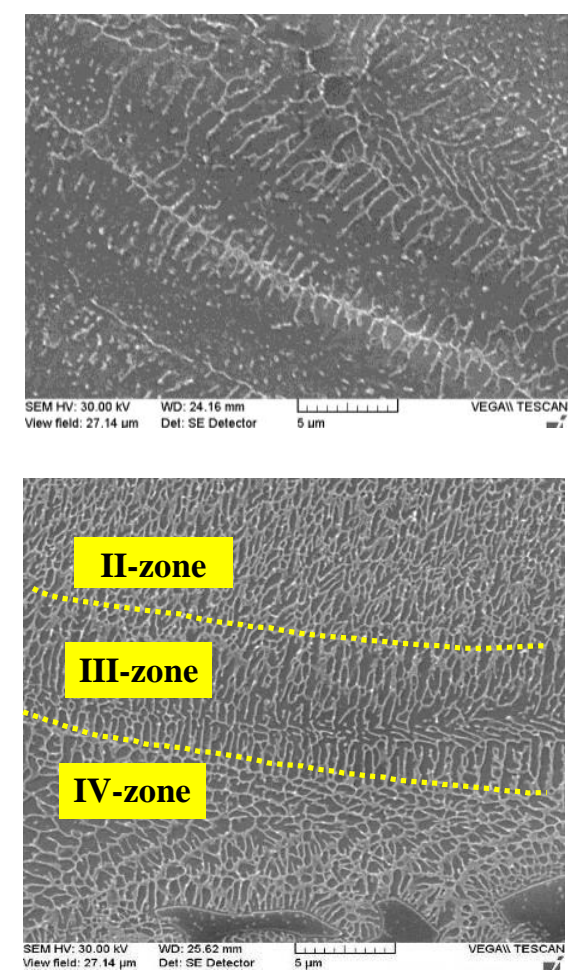

Fig. 5. Microstructure of AlZn10Si8 cast alloy after laser treatment: a) microstructure of laser affected zone, etch. Weck-Al, b) detail of the remelting zone, etch. $\left.\mathrm{H}_{3} \mathrm{PO}_{4}, \mathrm{SEM}, \mathrm{c}\right)$ the remelting zone,etch. $\mathrm{H}_{3} \mathrm{PO}_{4}$, SEM, d) detail of the remelting zone,etch. $\mathrm{H}_{3} \mathrm{PO}_{4}, \mathrm{SEM}$

High temperature of action the laser beam causes vaporization of some elements, possibly $\mathrm{Si}$, resulting in the Si particles in the melting occurs. Overheating the material Al-Zn-Si alloy laser hardening in the transition region refines eutectic silicon crystals (Fig. 6) there is a change or spheroidized of Si particles - modify the action of the laser (GHENG, H. 2001). The thickness of laser affected (remelted) zone was measured using the software NIS Elements 3.0. Results are presented in Fig. 7 and Table 2. Surface strengthening after laser treatment at different pulse power was observed by microhardness changes. With the increase of the power, the thickness and the width of remelting zone increase faster (Table 2), so does the hardness. By overloading laser power $(80 \mathrm{~W})$ we can observe decreasing of surface layer microhardness as relate probably to presence thermal cracks in the surface. 
a)

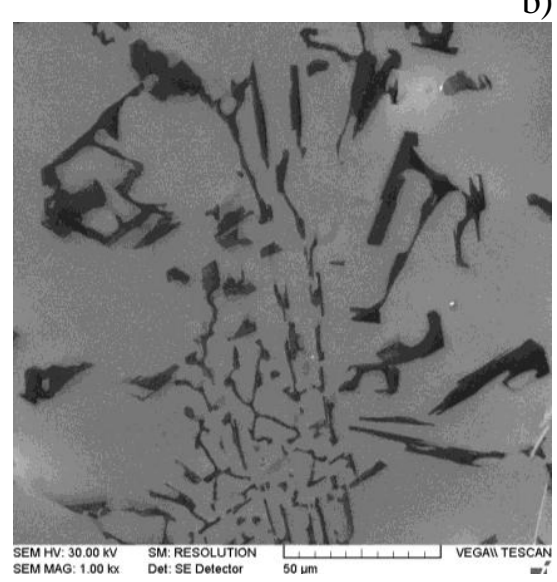

b)

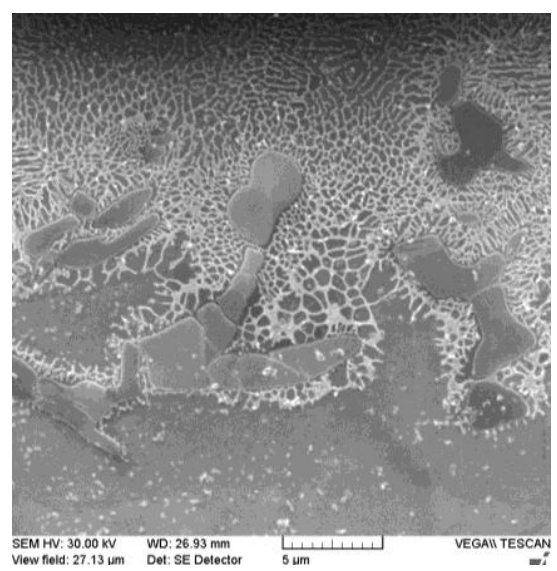

Fig. 6. Laser modification of Si particles, etch. $\mathrm{H}_{3} \mathrm{PO}_{4}$, SEM: a) unmodified Si particles, b) modified Si particles - detail

a)

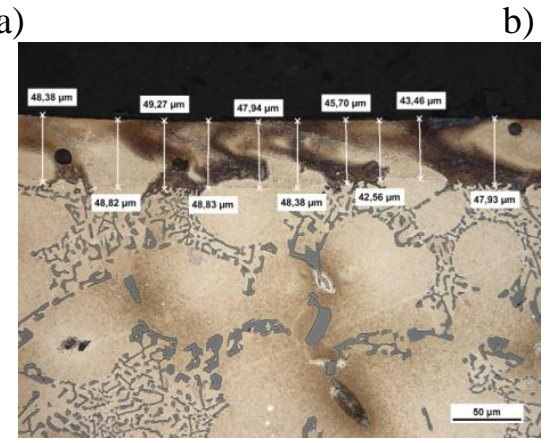

b)

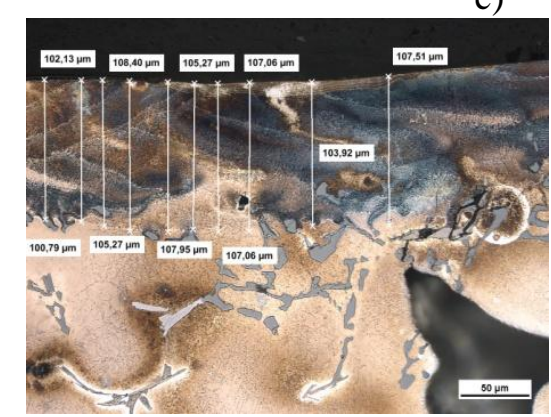

c)

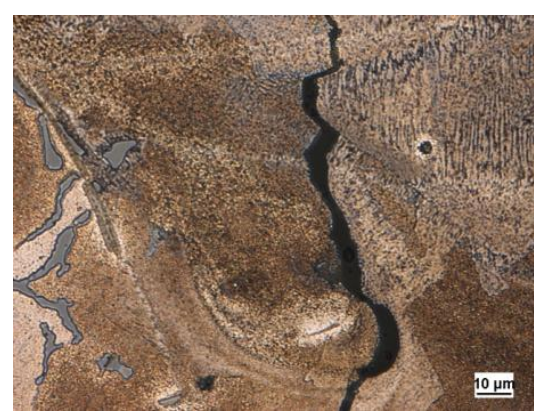

Fig. 7. The thickness of laser affected (remelted) zone, etch. Weck-Al: a) $50 \mathrm{~W}, b) 80 \mathrm{~W}, c$ ) thermal cracks in the surface layer

Table 2. Measurement result of layer after laser treatment

\begin{tabular}{|c|c|c|}
\hline $\mathrm{P}(\mathrm{W})$ & HV 0.01 & $\begin{array}{c}\text { Thickness of layer } \\
(\mu \mathrm{m})\end{array}$ \\
\hline 50 & 121.25 & 47.04 \\
\hline 80 & 110.5 & 108.09 \\
\hline
\end{tabular}

\section{Conclusion}

Due to the action of laser beam on the surface of the secondary alloy AlZn10Si8Mg there have been changes in the microstructure of the material:

- Melting area is $\alpha$-phase with much fine columnar dendrites morphology without the presence of Siparticles and intermetallic phases.

- In the transition area were observed grain refinement of eutectic Si (finer and rounder Si particles) as the modify action of the laser.

- By increasing the laser power the microhardness of surface layers decreases. In the surface layer were

observed cracks due to uneven heat transfer of the material.

\section{Acknowledgements}

The authors acknowledge the financial support of the project VEGA $N^{\circ} 1 / 0841 / 11$.

\section{References}

1. BORKOWSKI S., KNOP K. 2013. Visual control as a key factor in a production process of a company from automotive branch. Prodution Engineering Archives. No. 1. ISSN 2353-5156. p.25.

2. ĎURINíKOVÁ E. et al., 2011. Structural analysis of secondary alzn10si8mg cast alloy. In: Acta Metallurgica Slovaca, Vol. 17, No. 1, p. 4-10.

3. ĎURINíKOVÁ E. et al., 2010. Štruktúrna analýza zliatiny AlZn10Si8Mg, In: Letná škola únavy materiálov, Žilina, p. 174-177 (in Slovak). 
Eva Tillová et al.:, Effect of laser surface treatment, Vol. 2(1)/2014

4. GeNG, H., NiU, Y. et al., 2001. Laser surface strengthening process of Al-Si base alloy. Journal of Materials Sciences and Technology 17(S1), p. 115118.

5. http://en.wikipedia.org/wiki/Nd:YAG_laser

6. http://world-aluminium.org

7. http://www.kme.elf.stuba.sk/kme/buxus/docs/predmety/ AOL/Prednasky/Ohrev_povrchu_latok_laserovym_zvaz kom_doc.pdf

8. http://www.woodlaserengraver.com/category/nd-yaglaser/

9. LI, R. et al., 1996. Localised corrosion of laser surface melted 2024-T351 aluminium alloy. Surf. Coat. Technol. 81, p. 290-296.

10. WAtKIns, K. G. et al., 2003. Two new mechanisms for laser cleaning using Nd: YAG sources. J. Cult. Herit. 4, p. 59-64.

11. WAtKInS, K. G. et al., 1997. Microstructure and corrosion properties of laser surface processed aluminium alloys: a review. Mater. Sci. Eng. A 231, p.55-61.

12. WATKINS, K. G. et al., 1998. Influence of the overlapped area on the corrosion behaviour of laser treated aluminium alloys. Mater. Sci. Eng. A 252, p. 292-300.

13. Wong, R. C. P., Hoult, A. P., Kim, J. K., Yu, T. X., 1997. Improvement of adhesive bonding using a laser surface texturing process. J. Mater. Proc. Technol. 63, 579-584.

14. Www.alurheinfelden.com

15. www.sag.at 